\title{
A challenging case of recurrent disabling severe hypoglycemic episodes
}

\author{
Author (s) Kirthika Jeyaraman, Kevin Shotliff \\ Beta cell centre, Chelsea and Westminster hospital London, UK
}

\section{Case history}

- 33 year old landscape gardening labourer

- Insulin treated diabetes diagnosed at 3 weeks of age

- Referred to us at the age of 31 with 6-7 months of worsening hypoglycaemia with reduced / loss of warning symptoms

- No family history of Type 1 or Type 2 diabetes

\section{Collateral history from mother}

- Born at term by Forceps delivery

- Intubated for 3 minutes after birth

- Found soon after collapsed, 'looked blue' required re-intubation

- Persisting hypoglycaemia requiring IV dextrose,

hydrocortisone and glucagon

- Continued to become hypoglycaemic and 'started fitting'

- Further management:

IV Diazoxide, Paraldehyde, Phenobarbitone, Diazepam

\section{Surgical review during $1^{\text {st }}$ week of life}

- 5 days old:

* Partial pancreatectomy

\section{- 3 weeks old:}

* Subtotal pancreatectomy

* Insulin started (sliding scale initially)

Histology - Nesidioblastosis

\section{Histological features of Nesidioblastosis}

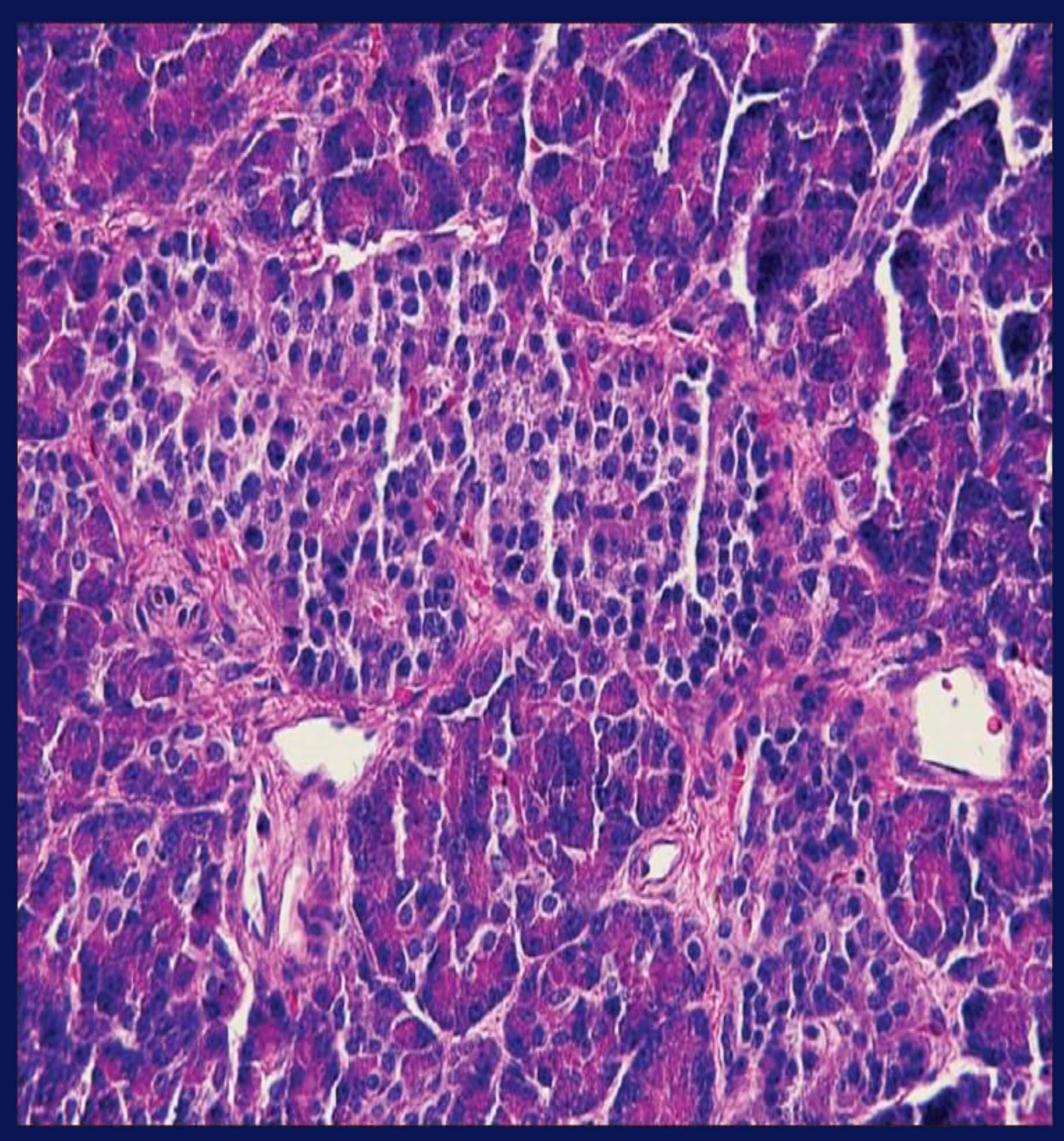

Irregular shaped hypertrophied islets

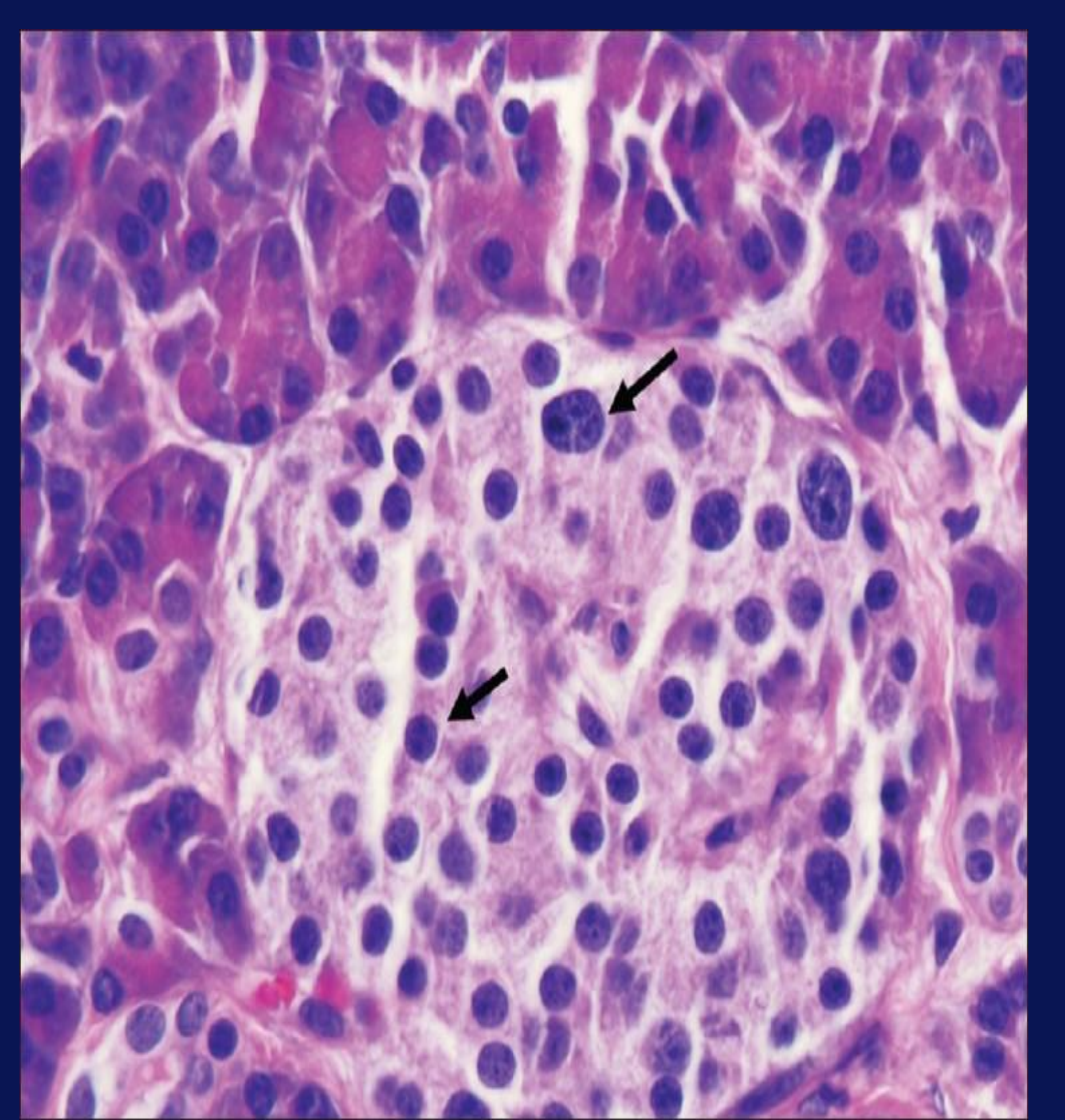

Islet cell pleomorphism. Marked difference in size of cells within same islet

\section{Clinic visit - 2010}

- 6-7 months of worsening hypoglycaemia with reduced / loss of warning symptoms

- 4-5 episodes of severe hypoglycaemia needing to go to local A\&E

- Medications:

Novorapid 12 units with breakfast, 20 units with lunch and dinner

Detemir 36 units mane, 38 units nocte

Creon ?dose 8-9/day with meals

\section{Clinical findings}

- Weight 79.5kg, Height 1.78m (BMI 25.1)

- CVS/RS/CNS - no abnormality detected

- Abdomen - small midline scar, no organomegaly

\section{Investigations}

- HbA1c 6.6\%, $49 \mathrm{mmol} / \mathrm{mol}$

- C-peptide detectable at $0.12 \mathrm{ug} / \mathrm{L}$ (NR 1.1-4.4)

- Insulin <0.5 mIU/L (NR 2.6-24.9)

- Sulphonylurea screen negative

- Normal renal, liver and thyroid profile

- $\underline{\mathrm{MRI}}$ and CT pancreas - possible small area of residual

pancreatic tissue in the region of head of pancreas

- Octreotide scan - no evidence of increased uptake in this area

\section{Discussion}

- Nesidioblastosis was first identified in 1938, when Laidlaw coined this ter to describe the neodifferentiation of islets of Langerhans from pancreatic ductal epithelium (a term since replaced by $\mathrm{PHHI}$ and $\mathrm{CHI}$ )

- Persistent hyperinsulinemic hypoglycemia of infancy (PHHI) represent the most common cause of hyperinsulinism in neonates. Currently, many authors prefer the term congenital hyperinsulinism (CHI)

-Severe recurrent hypoglycaemia associated with an inappropriate elevation of serum insulin, C-peptide, and proinsulin levels defines Congenital hyperinsulinism

- If left untreated, this condition can lead to brain damage or death secondary to severe hypoglycaemia

- $\mathrm{CHI}$ is often poorly responsive or unresponsive to medical management, necessitating $95 \%$ or near-total pancreatectomy

\section{Questions for audience}

This has been a challenging case of hypoglycemia.

Nesidioblastosis is a well recognized cause of persistent hyperinsulineamic hypoglycaemia of infancy. Although it was initially thought to affect only infants and children, numerous cases have been reported in adults of all ages but at a much lower incidence. Regardless of the pancreatectomy procedure used, hypoglycaemia may recur during long term follow up

- Should total pancreatectomy be considered for at this stage?

- How do we control his hypoglycaemia if this gets worse in the future? 